\title{
UC Cooperative Extension sensory analysis panel enhances the quality of California olive oil
}

\author{
by Paul M. Vossen and Alexandra Kicenik \\ Devarenne
}

California's olive oil industry has evolved from primarily a salvage operation of the table olive industry to a producer of world-class, premium, extra-virgin olive oil. In 1997, UC Cooperative Extension started the first California olive oil taste panel, which was officially recognized by the International Olive Council in 2001. Specific protocols were used to screen potential panelists and train them to identify defects and positive characteristics, identical to 43 other world taste panels. The UCCE panel helped the California Olive Oil Council develop a seal certification program using sensory analysis. Certification provides consumers with assurance that labeled oils are free of defects and warrant the "extra virgin" grade. Sensory evaluation using a unique UCCE profile sheet provides complete and detailed information about specific positive flavor characteristics of olive cultivars grown in California. The UCCE sensory panel has also contributed to a better understanding of the qualities of California olive oil and advancement of the industry by participating in research on pest management, cultural practices and processing.

$\mathrm{D}$ uring the California olive oil revival of the past two decades, a quiescent industry has come dramatically to life (see box, page 9). Acreage planted in oil olives is increasing rapidly. By fall 2010, an estimated 28,500 acres were growing in California, a doubling of acreage from 3 years prior.

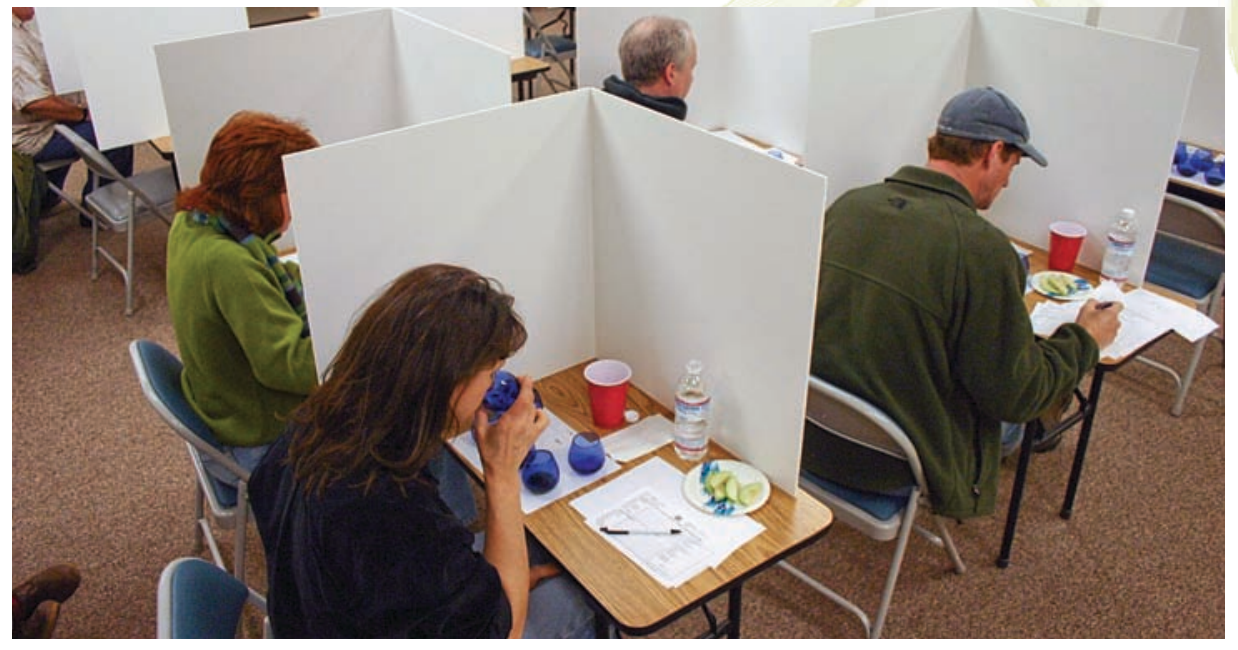

California sensory panel members evaluate oils at an official tasting.

Interest in planting new orchards is still high, but the economic crisis has reduced the rate of oil-olive acreage growth. A few large producers make about $80 \%$ of the state's olive oil, but more than $90 \%$ of the farms are small scale with less than 20 acres. Production of premium olive oil in California is predicted to double in the next 3 years from 800,000 to 1.6 million gallons. Many of these oils are excellent, taking top awards in global competitions.

But this was not always the case. The improvement in California's olive oil is due largely to the efforts of a scientifically selected and trained sensory evaluation panel. Only the most rudimentary quality testing on olive oil is currently being done by laboratory chemical analysis; a group of human beings following strict tasting protocols is now the standard tool for detecting, identifying and quantifying the many positive and negative attributes of olive oil.

Although people have been making and using olive oil for thousands of years, the methodical sensory analysis of olive oil is a recent development. Its use in measuring quality was advanced significantly in the early 1980s, when sensory researchers in Spain, Italy, Greece, Portugal and France began working together with the International Olive Oil Council (now the International Olive Council or
IOC) to develop the first official tasting methodology. Their work applied the principles of sensory science to olive oil. Sensory evaluation evokes, measures, analyzes and interprets the responses of tasters to the flavors they perceive.

Worldwide, sensory analysis has become a key part of how olive oils are rated for market grade, and it has been used to help growers and processors produce a higher-quality product. Since the late 1980s, many researchers have used sensory evaluation to characterize olive oil flavors attributable to cultivar (variety), fruit maturity, terroir, irrigation, tree nutrition, pest damage, fruit handling and processing methods. Researchers have also taught sensory short courses and workshops for industry professionals and consumers about olive oil styles and quality.

\section{Uses of a sensory panel}

A trained sensory panel is an invaluable tool. It provides an objective sensory evaluation of olive oil that can be used by regulators to enforce label standards that protect consumers, producers and processors from fraud in the industry. IOC quality standards are used globally to determine whether an oil should be graded and marketed as "extra virgin" or "virgin," or refined and then sold as "olive oil" (see box, page 10). In order for an oil to be graded as "extra virgin," it must pass several 
laboratory chemical analyses and be evaluated by a sensory panel. The olive oil must be free of defects and have some fruitiness.

Official IOC tastings that rate oils for compliance to trade standards note the intensity of any defects. Only three positive attributes - fruitiness (either green or ripe fruit), bitterness and pungency - are quantified on the profile sheet. The official IOC profile sheet includes five standard defects: fusty/ muddy sediment, musty, wineyvinegary, rancid and metallic. Space is left to note negative attributes other than the classic defects (IOC 2006, 2007c). Beyond evaluating by defined IOC standards, sensory panels help producers make better decisions regarding variety selection, pest management, cultural practices and harvest timing. With qualitative analysis, processors can also better select processing methods to maximize quality and assess how various cultivars might contribute desirable characteristics in blends.

\section{Sensory evaluation in research}

Variety. Sensory panels define the attributes of olive varieties and rate them according to the intensity of fruitiness, bitterness and pungency, but also provide an in-depth evaluation of fruit flavor characteristics. The content of volatile aromatics (aroma compounds emanating from the oil) and polyphenols (complex phytochemicals that act as antioxidants) make up much of an oil's flavor, and are highly variable between varieties. Qualitative analysis of the fruity characteristics of an olive oil provides valuable information about the sensory contributions of different cultivars, helping producers to select varieties and market product to consumers (Cimato et al. 1996; Romero et al. 2005; Tura et al. 2000; Uceda and Aguilera 2005; Vossen 2003, 2007a, 2007d).

Fruit maturity. Fruit ripeness can have a significant influence on the oil's flavor. Immature fruit produces oils with green fruity flavors such as freshcut grass, herbs, artichoke or mint. More mature fruit yields oils with ripe notes such as nutty, buttery, floral, apple, banana, berry or tropical. Sensory analysis of oils made from greener fruit has shown high bitterness and pungency, which correlates with laboratory analysis showing high polyphenol and antioxidant levels (Alba Mendoza et al. 1997; Romero and Díaz 2002; Vossen 2005).

Terroir. Climate, soil composition and other environmental factors that make up "terroir" may influence olive oil qualities, but this is a continuing area of research. Most scientists have indicated that the influence of terroir is minimal compared to variety and

fruit maturity, but some studies have shown that oils from different areas are notably different in flavor (table 1). Sensory characteristics have also been used to identify oils by protected growing region (appellation) (Aparicio et al. 1997; Ranalli et al. 1999; Tous et al. 1997; Vossen 2007c).

Irrigation. Irrigation is the most commonly manipulated grower practice that specifically influences oil sensory

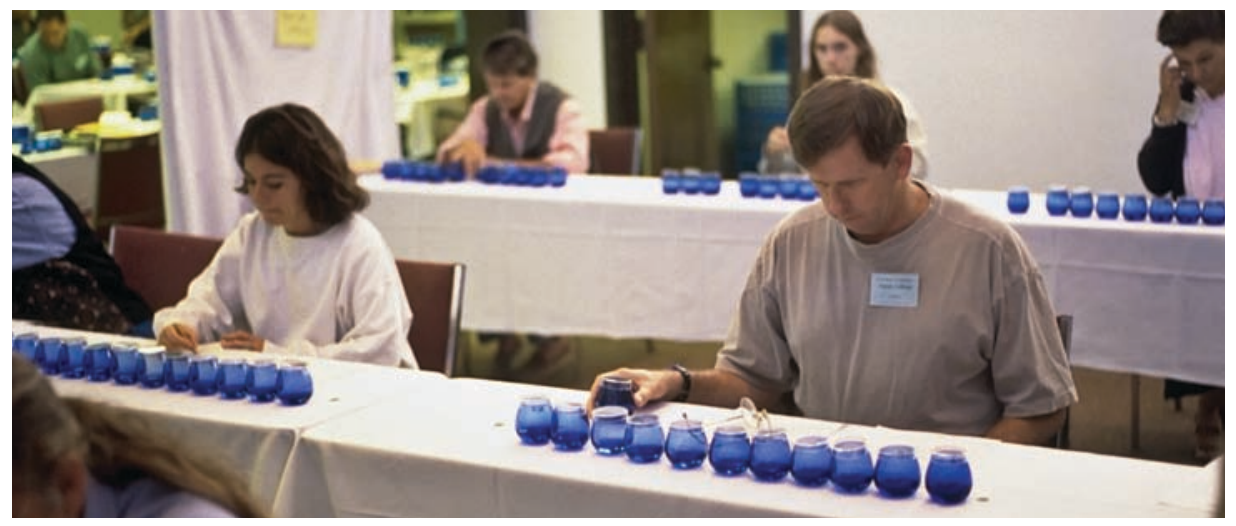

The sensory aptitude of potential tasters is screened by having them arrange oils along a scale for particular attribute intensities.

\section{Olive oil in California}

The olive came to California from Mexico with the Franciscan fathers. Although olive oil production likely started within a couple of decades of the 1769 founding of the first California mission in San Diego, the earliest written record is from 1803. After a period of decline in the mid-1800s, olive oil production expanded between 1870 and 1900; the state's first commercial olive oil mill is believed to have been established in Ventura County in 1871. Unable to compete with low-priced oil from Europe, around 1900 the California olive industry turned its attention to table olive production. Table olives dominated the domestic olive scene for more than 75 years. For years, the California olive oil industry was largely a salvage operation, using culls from table fruit production to produce low-quality oil for refining.

In the late 1980s, a small number of growers began to produce high-quality olive oil for the gourmet market. Some of these early producers harvested existing trees that had been regarded mostly as messy ornamentals for years. But other growers, for the first time in decades, planted olives with the intention of producing oil. Acreage of table olives declined during the same period, primarily because of competition from inexpensive imports in the Californiastyle black olive market.

A 2004 survey of the California olive oil industry found 528 growers in 38 counties, producing almost 400,000 gallons of oil on 6,170 acres. From 2005 to 2008 , another 13,400 acres were planted, and in the last 2 years an estimated 9,000 more have gone in, mostly in super-high-density orchard systems (see page 34 ). California olive oil currently represents only $2 \%$ of domestic consumption, so there is a vast market to be tapped. Since the domestic industry is producing extra-virgin olive oil that is as good as imports, consumer education and the enforcement of quality standards may be key elements in capturing more of the domestic market.

For more information go to: http://cesonoma.ucdavis.edu. 
qualities (table 2). Large flavor differences have been documented in oils from trees given different amounts of irrigation water (ranging from 15\% to $107 \%$ of seasonal need). Droughtstressed trees tend to produce excessively bitter and pungent oils. Trees maintained with a moderate water status (controlled deficit) tend to produce oils with higher overall fruitiness that is balanced with bitterness and pungency. Heavily watered trees generally produce bland olive oils with little fruitiness or pungency (Berenguer et al. 2006; Salas et al. 1997).

Olive fruit fly. Sensory evaluation of oils made in California from fruit with different levels of olive fruit fly damage showed that the conventional $10 \%$ threshold was often too conservative, and too generic to predict senory impacts. In blind sensory evaluations, no significant flavor differences could be detected in fresh oil from early damage by fly larva prior to the onset of soft fruit rot, even when fruit was 100\% damaged. In 2008, however, the sensory panel found that off flavors could immediately be detected when fruit rot ranged from $1 \%$ to $5 \%$. Therefore, with early harvest and rapid processing, minor olive fruit fly damage can be tolerated, which can save treatment costs and reduce environmental contamination (Hermoso et al. 2001; Vossen, unpublished data; Vossen and Kicenik Devarenne 2006a).

Harvest, transport and storage. Most olive oil defects come from improper handling of the fruit during and after harvest. If the fruit is compromised in any way, it should be milled within 24 hours of harvest. This includes broken skins, storage at temperatures above $40^{\circ} \mathrm{F}\left(5^{\circ} \mathrm{C}\right)$ or fermentation beginning in piled fruit (García et al. 1996).

Washing and leaf removal. In Italy and Spain, researchers found that when fruit was clean and dry (unwashed), it produced oils with a consistently better

\section{Olive oil definitions and regulations}

Extra virgin and virgin. "Extra virgin" is a grade of olive oil narrowly defined by the International Olive Council (IOC). Its standards require oil to be produced entirely by mechanical means, without the use of solvents, under temperatures that will not degrade the oil (less than $86^{\circ} \mathrm{F}\left[30^{\circ} \mathrm{C}\right]$ ). It must have a maximum free-fatty-acid level of less than $0.8 \%$ (an indication of the fruit's condition) and a peroxide value of less than 20 milliequivalent $\mathrm{O}_{2}$ (a measure of oxidation). Most importantly, a trained and IOC-recognized sensory evaluation panel must find it free from defects and possessing some degree of fruitiness. The next grade of olive oil is "virgin," which may have a free-fatty-acid level up to $2 \%$ and some slight flavor defects.

Common and lampante. The

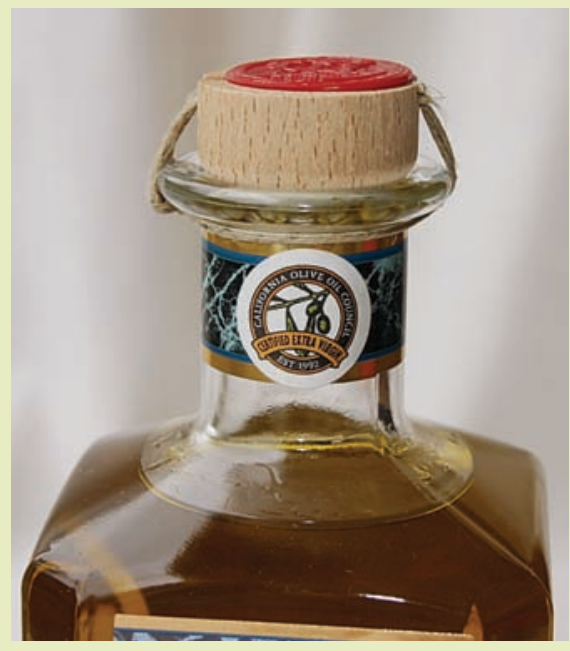

The California Olive Oil Council awards the extra-virgin certification seal to member oils that are defect free. grades "common" and "lampante" (lamp oil) are lower still, for oil possessing more pronounced defects. Lampante oil must be refined before it is usable.

While these standards are widely recognized in the United States, there is no guarantee that an oil labeled "extra virgin" meets IOC standards. In October 2010, new voluntary USDA standards for olive and olive pomace oil went into effect, essentially adopting the IOC laboratory and sensory standards. California, Connecticut and Oregon have done the same at the state level. Hopefully, these new standards will be broadly adhered to in the United States to protect both consumers and ethical producers. sensory rating than if clean and wet (washed) due to the lower moisture content of the paste. Normally, all leaves are removed, but researchers found that some leaves (up to $3 \%$ ) left in the olives during crushing gave the oil more bitterness, green fruitiness and green color. This could be desirable if these characteristics are lacking (Hermoso Fernández et al. 1991; Di Giovacchino et al. 1996).

Crushing. Differences in paste characteristics have been demonstrated to produce various effects on oil sensory quality. Finer pastes tend to release more oil that possesses greener color and stronger herbaceous, grassy, sweet almond and cypress wood flavors. Coarse paste tends to produce less bitter and pungent oils (Di Giovacchino 1996; Koutsaftakis et al. 2000).

Malaxation. Changing the time, temperature and amount of oxygen exposure during malaxation (slow mixing) of olive paste influences the oil's

TABLE 1. Sensory attributes of 'Arbequina' olive oils grown in three different zones in Spain

\begin{tabular}{lccc}
\hline Attribute & Siurana & Garrigues & Andalucía \\
\hline Fruity & 2.4 & 2.2 & 3.1 \\
Green & 1.5 & 1.4 & 1.8 \\
Bitter & 1.1 & 1.8 & 0.6 \\
Pungent & 1.6 & 1.7 & 0.6 \\
Sweet & 1.8 & 1.8 & 2.4 \\
Sensory & 7.7 & 7.4 & 8.9 \\
rating* & & & \\
\hline * European Union rating scale, 0-9 points. & \\
Source: Tous et al. 1997. & &
\end{tabular}

TABLE 2. Means of sensory characteristics of oils from trees receiving different amounts of irrigation

\begin{tabular}{|c|c|c|c|}
\hline $\begin{array}{l}\text { Treatment } \\
\text { (\% ETc)* }\end{array}$ & Fruity & Bitter & Pungent \\
\hline 15 & 3.60at & $6.00 a$ & $4.90 a$ \\
\hline 25 & $3.20 \mathrm{a}$ & $4.20 \mathrm{~b}$ & $3.90 \mathrm{~b}$ \\
\hline 40 & $2.70 \mathrm{~b}$ & $1.70 \mathrm{c}$ & $1.90 \mathrm{c}$ \\
\hline 57 & $2.60 \mathrm{~b}$ & $0.93 d$ & $1.10 d$ \\
\hline 71 & $2.10 \mathrm{c}$ & $0.30 d$ & $0.30 \mathrm{e}$ \\
\hline 89 & $1.80 \mathrm{c}$ & $0.22 d$ & $0.22 \mathrm{e}$ \\
\hline 107 & $1.70 \mathrm{c}$ & $0.20 d$ & $0.20 \mathrm{e}$ \\
\hline \multicolumn{4}{|c|}{$\begin{array}{l}\text { * Evapotranspiration rate (water use by olive trees) with a } \\
\text { coefficient corrected for olive trees compared to a general } \\
\text { reference rate. }\end{array}$} \\
\hline \multicolumn{4}{|c|}{$\begin{array}{l}\text { † Different letters indicate values significantly different at } \\
P=0.01 \text {. }\end{array}$} \\
\hline \multicolumn{4}{|c|}{ Source: Berenguer et al. 2006.} \\
\hline
\end{tabular}


sensory characteristics. Longer malaxation times increase oil yield, lower polyphenol levels and lower the levels of aromatic volatiles responsible for some fruity flavor characteristics. Raising the paste temperature causes greater extraction of polyphenols, but every $22^{\circ} \mathrm{F}$ $\left(12^{\circ} \mathrm{C}\right)$ increase in temperature doubles the loss of volatile aromatics. Paste malaxed at $95^{\circ} \mathrm{F}\left(35^{\circ} \mathrm{C}\right)$ produces oil that is sharply bitter compared with at $77^{\circ} \mathrm{F}$ $\left(25^{\circ} \mathrm{C}\right)$. Malaxation tanks that exclude oxygen significantly increase bitterness and pungency. Many researchers are currently investigating the effects of low oxygen exposure on aromatic compounds that influence fruitiness (Angerosa 2002; Di Giovacchino et al. 2002; Hermoso Fernández et al. 1991).

Extraction system. Press systems have consistently produced oils with more defects than continuous-flow systems. Sensory evaluation of oil from continuous-flow processing systems that use different amounts of added water have shown that oils are higher in fruitiness, bitterness, pungency and green character when less water is added (Alba Mendoza et al. 1996; Hermoso Fernández et al. 1998; Kicenik Devarenne and Vossen 2007a).

Oil styles and excellence recognition. Providing industry professionals with accurate evaluations of olive oil flavor characteristics is extremely important. With flavor profiles of their oils, producers can make well-informed decisions about the styles of olive oils they want to produce, and consequently, better olive oils. UC Cooperative Extension (UCCE) has produced several informative handouts on how to define extravirgin olive oil and interpret an olive oil label, and how untrained tasters can inadvertently promote the use of defective oils. Many untrained tasters are average consumers who are accustomed to defective flavors, identifying them with the taste of olive oil (Kicenik Devarenne and Vossen 2007b; Vossen 2007a; Vossen and Kicenik Devarenne 2006b).

\section{The California sensory panel}

During a 1996 study leave, farm advisor Paul Vossen realized that Europeans understood olive oil quality and were using sensory analysis to describe and promote positive characteristics. They were also using sensory analysis to weed out poor-quality oils and educate producers about defects, to help them avoid making production mistakes.

In 1997, the first California screening for sensory panel members was conducted at UC Davis, with the aid of Juan Ramon Izquierdo from the Spanish Arbitration Laboratory in Madrid. Using IOC procedures, potential panelists were screened for olfactory and gustatory sensitivity and also for motivation, availability and personality (IOC 2007a). Twenty people out of 75 were selected. Subsequent screenings added another 26 panelists. Altogether, 46 tasters were selected out of 217 applicants (21\%). About half of those have chosen to remain active.

Trained panel members' minds and palates must become calibrated over time to an absolute scale of intensities for all the common flavor attributes of olive oil. The calibration process takes several years and is not permanent; panelists must continually receive training if they are to remain sharp. Training is conducted by a panel leader who provides the group of tasters with samples of known characteristics and intensities in order for them to learn and remember specific positive and negative attributes. Panelists must also taste oils from all over the world to learn the characteristics of each variety, so that varietal differences are not confused with defects.

The IOC recognizes sensory panels that are approved by a government agency such as the U.S. Department of Agriculture. Panels from around the world take compulsory proficiency tests called ring tests, in which they all taste and rate the same five oils. The results are compared using a standard procedure that is analyzed statistically for variability, accuracy and uniformity. In 2001, the UCCE sensory panel participated in a series of ring tests and became one of 41 officially recognized IOC taste panels, the first one in the United States to have received such recognition (IOC 2007b). (Many of the original tasters are now members of the
UC Davis Olive Oil Taste Panel, recently certified by the IOC.)

\section{Tasting protocols}

Samples are presented "blind" and in the most appropriate order, so that errors of contrast are minimized (see box, page 12). Oils are identified with a random three-digit number or letter combination that is not familiar in any way, to prevent order bias. Special blue glasses are used to obscure the oil color, so that color bias does not influence the panelists' evaluations, and tasters are isolated from one another with dividers. For the most accurate evaluation, olive oils are warmed to $80^{\circ} \mathrm{F}\left(26.5^{\circ} \mathrm{C}\right)$ on a warming mat. Because flavors based in oil coat the mouth, throat and nasal cavity, they tend to linger, which influences the reaction to subsequent samples and quickly fatigues the senses. A resting time of 5 minutes is required between oils, and green apples and water are used as palate cleansers to minimize sensory fatigue. Panelists usually taste from three to five oils in 30 minutes (IOC 2007c).

Sensory panelists place a short, vertical mark on a horizontal, unstructured, 10-centimeter line scale where the flavor intensity is perceived to be. Data on profile sheets containing individual oil ratings is compiled by a technician and analyzed with a statistical computer program developed by the IOC. The software places each oil into a specific category - extra virgin, virgin, common or lampante - based on the IOC standards for defect-intensity levels and the presence of fruity characteristics.

The minimum IOC sensory definition of an extra-virgin oil, for example, is one in which the mean score of the 
eight panelists is zero defects with some fruitiness. This means that five out of eight must agree in their profile-sheet characterizations. If the coefficient of variation (relative robust standard deviation) of the main defect is greater than $20 \%$ in a defective oil, or greater than $10 \%$ in an extra-virgin oil for the fruitiness characteristic, the test must be repeated.

Tasters must be very close in identifying the primary defect in each oil, if it has one, and the intensities of the defect must be within 2 points on the 10-centimeter scale. For fruitiness, the intensity must be within 1 point on the scale. The statistical program makes a calculation (median, interquartile interval, robust standard deviation, relative robust and standard deviation) based on each panelist's evaluation of each oil, and a minimum of eight panelists must be used for an official oil evaluation (IOC 1999).

\section{UC and the olive oil industry}

In 1999, the California sensory panel began providing feedback to the state's olive oil industry in the form of a seal certification program, in partnership with the California Olive Oil Council

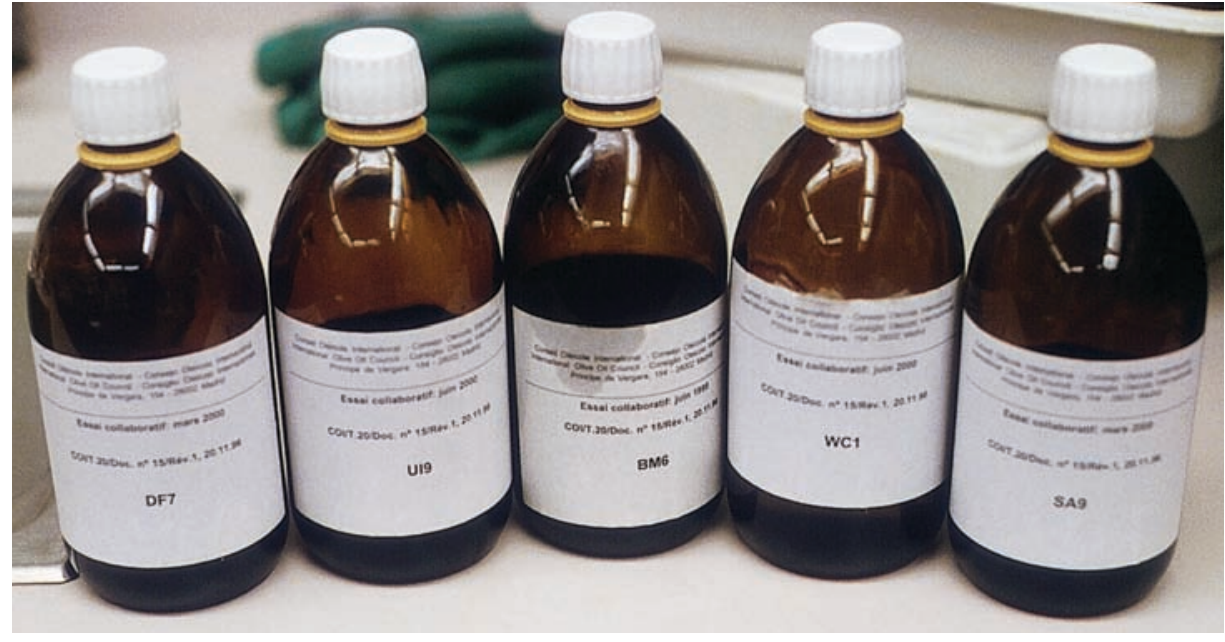

The International Olive Council conducts "ring tests," sending the same five oils to panels around the world for testing to ensure that its standards are being upheld.
(COOC), a trade organization. UCCE farm advisor Vossen was responsible for training the sensory panel and maintaining scientific protocol. The COOC seal was awarded to oils that the sensory panel judged "extra virgin" according to IOC standards. Producers also benefited from panelist comments regarding their oil's characteristics. If an oil failed certification, the farm advisor confidentially informed the producer of the nature of the defect and its

\section{How to taste olive oil}

Olive oil is best tasted in a blue, tulip-shaped, stemless glass. The tasting glass is covered with either a lid or hand, and the oil gently swirled. The open glass is placed close to the nose and the taster takes a deep breath, making a mental note of the aroma, since much of what we call flavor is actually smell. Next, the taster sips about 5 milliliters of oil and holds it in their mouth for 10 seconds, taking care to coat all parts of the mouth and tongue. While

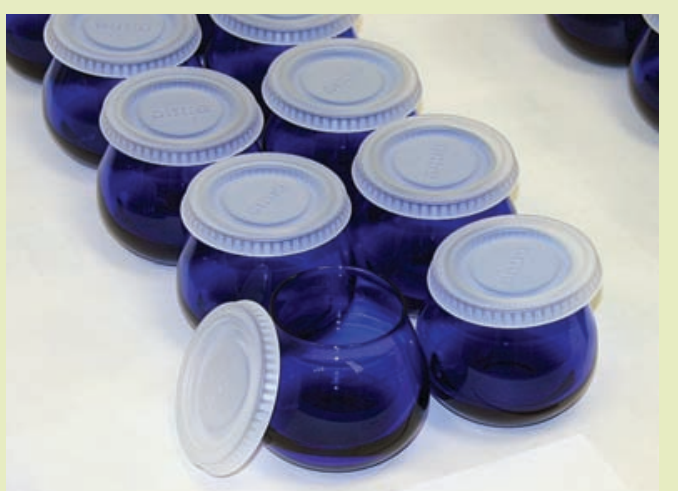

Blue glasses are used to taste olive oil, in order to prevent color bias.

the oil is in the mouth, air is sucked in to further volatilize its aromatic components before swallowing. Then the mouth is closed while the taster breathes out through the nose. The retronasal cavity connecting the mouth to the olfactory area allows the volatile aromas to be perceived once again.

The mouth and throat detect flavors such as bitterness, pungency, sweetness and astringency. Most people taste bitterness primarily toward the back of the tongue and mouth. Pungency is a physical irritation perceived in the throat, which is why it is essential to swallow some of the oil in order to appreciate all of its sensory characteristics. likely cause. From 1999 through 2004, the number of defective oils dramatically declined from $50 \%$ to less than 3\%. If an oil was deemed defect-free (and therefore certifiable) but there was room for improvement, the panel's comments regarding harvest maturity or other factors were passed along to the producer. The COOC seal was the first attempt by the domestic industry to give consumers an assurance of quality when purchasing California olive oil.

In 2005, a new UCCE profile sheet was developed for more detailed analysis of extra-virgin olive oils in California. It records taster impressions of additional aspects, including the oil's harmony and complexity. By selecting from a list of descriptors such as artichoke, banana, almond or fresh-cut grass, the tasters note undertones in the olive oil. Previous sensory panel analysis emphasized defect identification. Descriptive analysis provides extremely valuable data on the more subtle and complex aspects of olive oil. This can help producers adjust harvest timing, tailor processing methods to particular varieties and pinpoint attributes for blending.

UC has also been addressing the needs of the California olive oil industry with training programs, such as the 2-day Olive Oil Sensory Evaluation Short Course, taught once or twice per year since 1999. Likewise, special trainings have been conducted for chefs, food writers, producers, consumers and educators. In addition, UCCE short courses on olive production 
topics, regional grower meetings and field days have also provided valuable science-based information. Two UC Division of Agriculture and Natural Resources publications, the Olive Production Manual and Organic Olive Production Manual, continue this tradition.

\section{Looking to the future}

Due to UC research and support, and the efforts of the sensory panel volunteers, it has become a rarity to find defects in a California olive oil. Research continues to explore the effect of terroir on olive oil, and a database is being created of characteristics in single varietal oils grown in different parts of the state.

\section{References}

Alba Mendoza J, Hidalgo F, Casado MA, et al. 1996. Características de los aceites de olive de primera y segunda cetrifugación. Grasas Aceites 47(3):163-81. Alba Mendoza J, Izquierdo JR, Gutiérrez Rosales F. 1997. Aceite de Olive Virgen Análisis Sensorial. Editorial Agrícola Española, S.A. Artes Gráficas COIMOFF, S.A. Madrid, Spain

Angerosa F. 2002. Influence of volatile compounds on virgin olive oil quality evaluated by analytical approaches and sensory panels. Eur J Lipid Sci Technol 104:639-60.

Aparicio R, Morales MT, Alonso V. 1997. Authentication of European extra-virgin olive oils by their chemical compounds, sensory descriptors and consumer attitudes. J Agr Food Chem 45:1046-83.

Berenguer MJ, Vossen PM, Grattan SR, et al. 2006. Tree irrigation levels for optimum chemical and sensory properties of olive oil. HortScience 41(2):427-32. Cimato A, Baldini A, Caselli S, et al. 1996. Observations on Tuscan olive germplasm. 3: Analytical and sensory characteristics of single-variety olive oils. Olivae 62:46-51. International Olive Oil Council, Madrid, Spain

Di Giovacchino L. 1996. Influence of extraction systems on olive oil quality. Olivae 63:52-63. International Olive Oil Council, Madrid, Spain.

Di Giovacchino L, Angarosa F, Giacinto D. 1996. Effect of mixing leaves with olives on organoleptic quality of oil obtained by centrifugation. J Am Oil Chem Soc 73:371-4

Di Giovacchino L, Costantini N, Ferrante ML, et al. 2002. Influence of malaxation time of olive paste on oil extraction yields, chemical and organoleptic characteristics of virgin olive oil obtained by a centrifuga decanter. Grasas Aceites 53:179-86.

García JM, Gutierrez F, Castellano JM, et al. 1996. Influence of storage temperature on fruit ripening and olive quality. J Agr Food Chem 44:264-7.

Hermoso Fernández M, Gonzáles J, Uceda M, et al. 1998. Elaboración de aceite de oliva de calidad II Obtención por el sistema de dos fases. Manual from the Estación de Olivicultura y Elaiotecnia. Finca "Venta del Llano" Mengíbar (Jaén), Spain. Junta de Andalucía Vol 61.

Hermoso Fernández M, Uceda M, García-Ortiz A, et al. 1991. Elaboración de aceite de oliva de calidad. Manual from the Estación de Olivicultura y Elaiotecnia. Finca "Venta del Llano" Mengíbar (Jaén), Spain. Junta de Andalucía Vol 5
This will help growers select varieties that are horticulturally suited to their location. Ongoing research on how olive fruit fly can damage the sensory aspects of olive oil will help producers further adjust their pest control measures to minimize environmental and financial impacts, while preserving oil quality. A research project comparing different processing systems will provide valuable information for producers seeking the best methods for their particular fruit, depending on variety and ripeness.

The UCCE sensory panel is providing feedback on specific flavor characteristics of individual oils that helps producers to choose varieties, adjust

Hermoso JF, Romero A, Tous J, et al. 2001. Incidencia del sistema de recolección en la calidad del aceite de oliva en el sur de Cataluña. IV Congreso Ibérico de Ciencias Hortícolas. Cáceres, Mayo. p 2012-20.

[IOC] International Olive Council. 1999. Organoleptic assessment of virgin olive oil - computer program Excel file - statistical analysis. COI/T.20/Doc No 15/Rev. 1

IOC. 2006. Trade standard applying to olive oils and olive pomace oils. COI/T.15/NC No 3/Rev 2, Nov 24, 2006.

IOC. 2007a. Guide for selection, training and monitoring of skilled olive oil tasters. COI/T.20/Doc No 14/Rev 2, Sept 2007

IOC. 2007b. Guidelines for the accreditation of sensory testing laboratories with particular reference to virgin olive oil according to standards ISO/IEC 17025:2005. COI/T.28 Doc No 1, Sept 2007

IOC. 2007c. Sensory analysis of olive oil - method for the organoleptic assessment of virgin olive oil. $\mathrm{COI} / \mathrm{T}$. 20/Doc No 15/ Rev 2, Sept 2007.

Kicenik Devarenne A, Vossen PM. 2007a. A report on California experiments with different olive oil mills. Proceedings-abstracts of Beyond Extra Virgin: Italo-Californian Olive Oil Conference, UC Davis, May 22-23. California Institute of Food and Agricultural Research. p 34

Kicenik Devarenne A, Vossen PM. 2007b. Cook's Illustrated, Dec. 2006: Comparison of olive oils revisited Handout - Proc Sensory Evaluation of Olive Oil short course, September 28-29. UC Davis Extension.

Koutsaftakis A, Kotsifaki F, Papamanolioudaki A, Stefanoudaki E. 2000. Effect of olive crushing parameters on the qualitative characteristics of virgin olive oil. In: Vitagliano C, Martelli GP (eds.). Proc 4th Intl Symp Olive Growing. Acta Hort 586.

Ranalli A, De Mattia G, Batumi M, Proietti P. 1999. Quality of virgin olive oil as influenced by origin area. Grasas Aceites 50(4):249-59.

Romero A, Díaz I. 2002. Optimal harvesting period for 'Arbequina' olive cultivar in Catalonia (Spain). In: Vitagliano C, Martelli GP (eds.). Proc 4th Intl Symp on Olive Growing. Acta Hort 586.

Romero A, Tous J, Guerrero L. 2005. Caracterización sensorial del aceite - Capitulo 15. (Banco de Germoplasma de Cataluña.) In: Rallo L, et al. (eds.) Variedades de Olivo en España (Libro II: Variabilidad y selección). Junta de Andalucía, MAPA y Ediciones Mundi-Prensa, Madrid. harvest maturities, schedule irrigation and generally improve the quality of their oils. California-specific data produced by the sensory panel - using internationally recognized scientific standards and methods - will continue to be essential to the growth of the California olive oil industry.

Paul M. Vossen is Farm Advisor, UC Cooperative Extension, Sonoma and Marin counties; and A. Kicenik Devarenne is Freelance Olive Oil Consultant, Writer and Educator, Sonoma County.

Shermain D. Hardesty, Specialist in the UC Davis Department of Agricultural and Resource Economics, served as Guest Associate Editor for this article.

Salas J, Pastor M, Castro J, Vega V. 1997. Influencia de riego sobre la composición y características organolépticas del aceite de oliva. Grasas Aceites 48(2):74-82.

Tous JM, Romero A, Plana J, et al. 1997. Chemical and sensory characteristics of 'Arbequina' olive oil obtained in different growing areas of Spain. Grasas Aceites 48(6):415-24

Tura D, Failla O, Bassi D, Serraiocco A. 2000. Sensory and chemical analyses of monovarietal olive oils from Lake Garda (Northern Italy). In: Vitagliano C, Martell GP (eds.). Proc 4th Intl Symp on Olive Growing, Valenzano, Italy. Acta Hort 586:595-8.

Uceda M, Aguilera M. 2005. Caracterización sensorial del aceite. Capitulo 15. (Banco de Germoplasma Mundial de Córdoba.) In: Rallo L, et al. (eds.). Variedades de Olivo en España (Libro II: Variabilidad y selección). Junta Andalucía, MAPA y Ediciones Mundi-Prensa, Madrid

Vossen PM. 2003. California Arbequina and Arbosana olive oils get a very high rating from the local tasting panel. OLINT Mag 2:15 (special English ed.).

Vossen PM. 2005. Variety and maturity: The two largest influences on olive oil quality. UNICO website Italian American Service Organization. http:// cesonoma.ucdavis.edu/files/27177.pdf.

Vossen PM. 2007a. Core issues grant report: California's unique olive oil identity. https://ucanr.org/cig/ programs/programswork/annualreportview.cfm.

Vossen PM. 2007b. Olive oil: History, production and characteristics of the world's classic oils - workshop. Mediterranean fruits: Ancient history and modern promise. HortScience 42(5):1093-100.

Vossen PM. 2007c. Orchard practices and olive oil quality. Proceedings-abstracts of Beyond Extra Virgin Italo-Californian Olive Oil Conference. UC Davis. May 22-23. California Institute of Food and Agricultural Research. p 23

Vossen PM. 2007d. Site, varieties and production systems for organic olives. In: Organic Olive Production Manual. UC ANR Pub 3505. Oakland CA.

Vossen PM, Kicenik Devarenne A. 2006a. Comparison of mass trapping, barrier film and spinosad bait for the control of olive fruit fly in small-scale orchards and landscapes in coastal California. Proc Olivebioteq 2:267-74. Marsala, Italy.

Vossen PM, Kicenik Devarenne A. 2006b. What is extra virgin olive oil? - The vocabulary of an olive oil label. Handout - Proc Sensory Evaluation of Olive Oil short course, September 28-29, UC Davis Extension. 